\title{
UWAGI O POLIGENEZIE RZEŹBY GÓR (NA PRZYKŁADZIE KARPAT)
}

\author{
The remarks on the polygenesis of mountains relief (exemplified by the Carpathians)
}

\author{
LESZEK STARKEL*
}

\begin{abstract}
Zarys treści. Rzeźba Karpat ma cechy rzeźby poligenicznej i polichronicznej. O poligenezie mówimy w dwojakim sensie. Młode formy modelowane są obecnie przy współdziałaniu różnych procesów (najczęściej erozji wody płynącej, sufozji i ruchów masowych). Zasadnicze formy obecnej rzeźby zostały przeważnie ukształtowane w odległej przeszłości w zmieniających się warunkach klimatycznych i tektonicznych. Oddziedziczona rzeźba dotąd zachowana była także w zależności od odporności skał podłoża stale adaptowana do nowych warunków. Szczególnie wyraźny zapis tej adaptacji dotyczy w analizowanym regionie ostatniego cyklu glacjalno-interglacjalnego czwartorzędu.
\end{abstract}

Slowa kluczowe: poligeneza rzeźby, rzeźba polichroniczna, Karpaty

Abstract. The relief of the Carpathians has the features of a polygenic and polychronic landscape. On polygenesis, we may talk in a double context. The young forms are developing at the present time by cooperation of various processes (mainly erosion of flowing water, piping and gravitational movements). The fundamental forms of the existing mountain relief were created usually in the distant past under varying tectonic and climatic conditions. The inherited relief has been preserved depending on the resistance of bedrock being permanently adapted to changing conditions. Particularly distinct markers of that adaptation in the Carpathians were left by the last glacial-interglacial cycle.

Keywords: polygenic relief, polychronic relief, Carpathians

\section{Wprowadzenie}

Cechą istniejącej rzeźby gór jest poligeneza. Korzenie rzeźby tkwią przeważnie w bardzo odległej przeszłości. Równocześnie postępujące stale zmiany są efektem współdziałania różnych procesów, przeważnie uwarunkowanych klimatycznymi zmianami, rzadziej ruchami tektonicznymi, a ostatnio także ingerencją człowieka (Starkel 2014).

Większość obecnie rozwijających się form stokowych i dolinnych jest efektem zróżnicowanych przestrzennie różnych procesów denudacyjnych, które ulegają przemianom w czasie.

O poligenezie rzeźby możemy zatem mówić w dwojakim sensie. Formy dziś powstające modelowane są albo przez długotrwający proces sekularny, albo przez szereg procesów ekstremalnych, których rola $\mathrm{w}$ trakcie dojrzewania tych form lub adaptacji do nowych warunków może ulegać zmianie (Starkel 1986). Mówimy o poligenezie współcześnie powstających form.
Równocześnie areną działających dziś procesów jest rzeźba, odziedziczona $\mathrm{z}$ okresów o innym klimacie i różnych procesach tektonicznych, której przetrwanie zależało przede wszystkim od odporności skał podłoża. Mówimy o rzeźbie metachronicznej, która była stale dopasowywana do zmieniających się warunków klimatycznych i baz erozyjnych.

\section{Poligeneza współczesna}

Rzeźbę dzisiejszej strefy umiarkowanej Europy zajętej poza wysokimi pasmami przez piętra leśne charakteryzują $\mathrm{w}$ przewadze stoki wypukło-wklęsłe, niekiedy podcięte przez erozję boczną, odziedziczone po morfogenezie peryglacjalnej (Starkel 1960, 2005). Procesami sekularnymi, które dziś ją modelują są ługowanie i spłukiwanie. Istotne zmiany następują po przekroczeniu wartości progowych trzech składowych obiegu wody (spływu powierzchniowego, infiltracji i spływu śródpokrywowego), odzwierciedlających się $\mathrm{w}$ spłukiwaniu (wraz z erozją

\footnotetext{
* Instytut Geografii i Przestrzennego Zagospodarowania PAN, ul. Św. Jana 22, 31-018 Kraków
} 
linijną), sufozji (często ze związanym z nią ługowaniem) i procesach osuwiskowych.

Staje się to częściej możliwe po zniszczeniu zwartej szaty roślinnej. Dominujące w naturalnych ekosystemach procesy sekularne o małym natężeniu nie stwarzają warunków do rozwoju nowych form poligenicznych, wpływając jedynie na przekształcenie pokryw glebowych.

Spłukiwanie na wylesionych uprawianych stokach prowadzi do powstawania żłobin a przy natężeniach opadów $1-4 \mathrm{~mm} / \mathrm{min}$ debrzy i wąwozów (Gil 1998; Starkel 1997). Przewaga spływu śródpokrywowego w czasie opadów rozlewnych prowadzi do powstawania kanałów, ślepych dolinek sufozyjnych i w końcu otwartych wąwozów (Czeppe 1960; Starkel 1960). Szczególnie aktywnie rozwijają się odcinki źródłowe (Wrońska-Wałach 2009). Rosnąca pojemność wodna zwietrzelin prowadzi w czasie długotrwałych opadów do uplastycznienia i upłynnienia gruntów i ruchów masowych (Gil, Starkel 1979).

Te trzy grupy procesów współdziałając ze sobą, prowadzą do powstawania na stokach rozcięć typu wąwozów lub wciosów, które w miarę dojrzewania przekształcają się w dolinki płaskodenne a nawet nieckowate (rys. 1) (Starkel 1960, 2011).

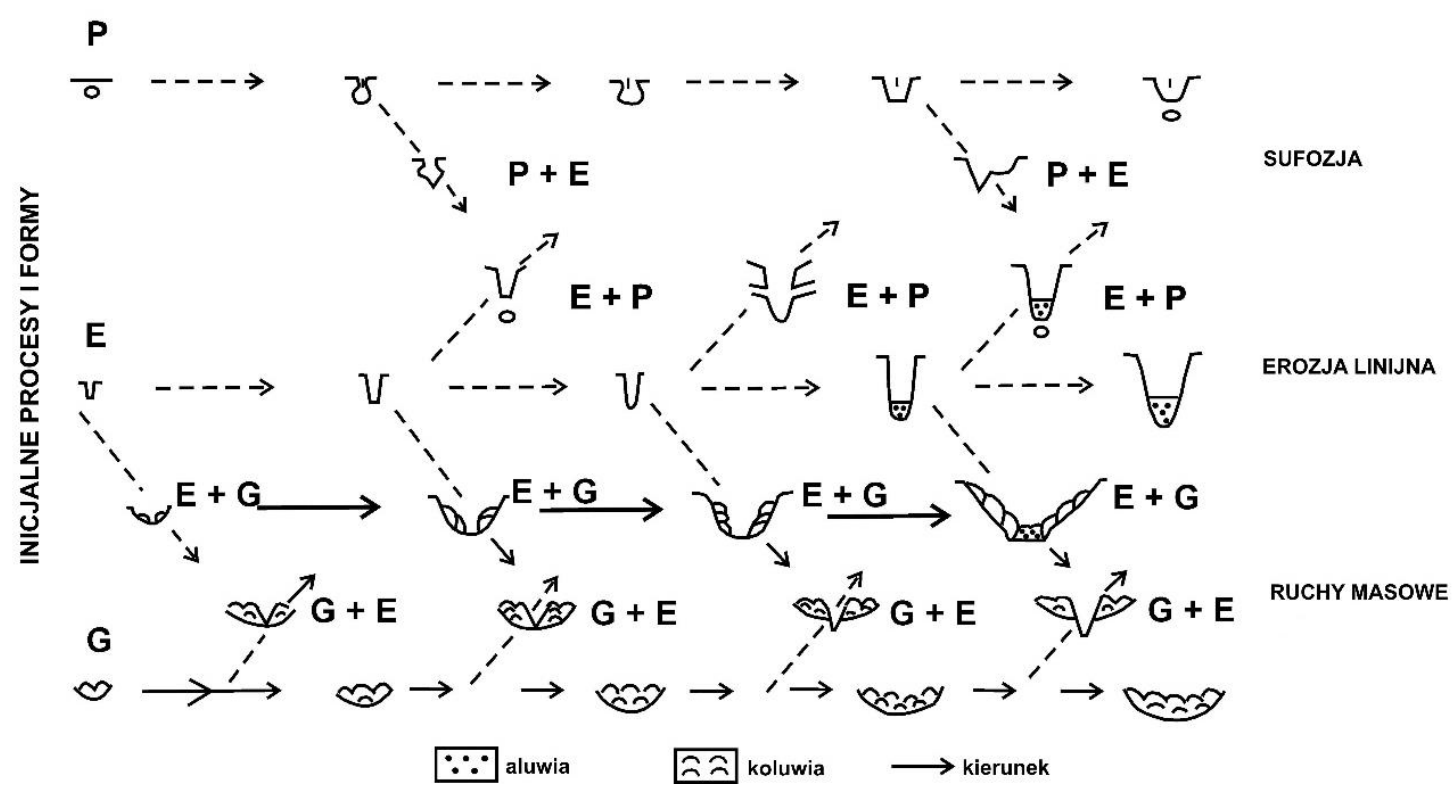

\footnotetext{
Rys. 1. Współdziałanie trzech procesów w ewolucji małych dolin erozji linijnej (E), sufozji (P) i ruchów masowych $(\mathrm{G})$

strzałki pokazują kierunek w przekształcaniu przekroju poprzecznego (Starkel 2011)
}

Coexistence of three processes in the evolution of gullies: erosion (E), piping $(\mathrm{P})$ and mass movements $(\mathrm{G})$ arrows show directions in the evolution of the transversal profile (Starkel 2011)

W czasie intensywnych opadów dochodzi do zaburzenia równowagi mas na większych powierzchniach i powstawania lub odnawiania dużych skalnych osuwisk, których dalszy rozwój zależy m.in. od możliwości odprowadzania rumowisk przez sieć rzeczną. Klasycznym przykładem może być szczegółowo zbadane osuwisko Zapadle w dolinie Bielanki (Gil, Kotarba 1977) i osuwisko na zboczu w dolinie Ropy (Dauksza, Kotarba 1973). Duże formy osuwiskowe są często drenowane przez stale odwadniane i pogłębiane rozcięcia, w których nisze lejów źródłowych ulegają cofaniu (Starkel 1960; Ziętara 1968).

W kształtowaniu nowych form istotną rolę odegrały zdarzenia ekstremalne, których charakter i funkcja zmienia się wraz z wysokością. W Tatrach w piętrze krioniwalnym ponad granicą lasu istotną rolę odgrywają procesy mrozowe, które modelują zarówno odziedziczone po zlodowaceniu ściany skalne, jak i przekształcane stożki usypiskowe i łagodne podnóża (Kotarba 1984; Rączkowska 2007). Są to krioniwalne procesy grawitacyjne wzbogacane przez letnie 
opady ulewne, które uruchamiają spływy gruzowe także niżej w piętrach leśnych (Kotarba 1994). Analiza termiki i opadów w cyklu rocznym w strefie górnej granicy lasu przeprowadzona przez Kłapę (1980) wykazała, że szczególne znaczenie odgrywa koegzystencja letniej pory pluwialnej i dwóch krótkich przejściowych pór niweopluwialnej i pluwioniwalnej z częstymi przejściami temperatury przez $0^{\circ}$, które łącznie decydują o rozwoju w tym piętrze stożków piargowych (Kotarba 1997).

\section{Poligeneza rzeźby odziedziczonej}

Rzeźba denudacyjna gór i wyżyn Europy środkowej ma starsze założenia, sięgające orogenezy alpejskiej (Karpaty) a nawet okresów wcześniejszych (Sudety i Góry Świętokrzyskie), może też dotyczyć podniesionych obszarów platformowych. Poszczególne etapy podnoszenia, rozcinania i zrównywania znajdują swe odbicie w piętrowości form rzeźby, które na podstawie nielicznie zachowanych fragmentów pokryw zwietrzelinowych lub na przedpolu osadowych datowane są na różne okresy geologiczne. Wyżej położone elementy rzeźby (starsze) zbudowane są na ogół z bardziej odpornych skał, a ich spłaszczenia przyjmowane były za resztki kilku schodowych powierzchni zrównań lub pedymentów (Klimaszewski 1965; Starkel 1965, 2014). Mają one jednak charakter strukturalny, związany $\mathrm{z}$ niedawno rozpoznaną tektoniczną transformacją $\mathrm{w}$ etapie regresji nasuwczej związanej z kolapsem grawitacyjnym (Jankowski, Margielewski 2014).

Najmłodszy i najniższy z poziomów w Karpatach fliszowych tzw. przydolinny datowany jest na dolny czwartorzęd (por. Zuchiewicz 2010). Poziomy spłaszczeń nie odzwierciedlają idealnie pierwotnej rzeźby strukturalnej, która została zdegradowana. Świadczą o tym leżące niżej pokrywy stokowe, jak i powstałe w obrębie grzbietów czwartorzędowe terasy krioplanacyjne (Ziętara 2002).

Badania stokowych pokryw peryglacjalnych z ostatniego glacjału (Dziewański, Starkel 1967; Klimaszewski 1971) jak też zachowanych kriopedymentów (Czudek, Demek 1973; Czudek 2001) wskazują na istotną rolę rozwoju i degradacji zmarzliny w przekształceniu rzeźby fliszowych Karpat. Śladem skali obniżenia w ostatnim glacjale grzbietów wododzielnych, zbudowanych z mniej odpornych ogniw fliszu, są miąższe do 15-20 m pokrywy soliflukcyjne i deluwialne złożone u podnóży stoków (Dziewański, Starkel 1967), będące produktem procesów sekularnych, a w niewielkim stopniu także ekstremalnych. Szczegółowe badania nad stratygrafią osadów rzecznych i stokowych z ostatniego glacjału (Starkel i in. 2007; Gębica i in. 2015) pokazują, że mieliśmy w ciągu tych 100 tys. lat szereg wahań klimatycznych różnej długości. Szczególne przekształcenia miały miejsce w czasie kilku gwałtownych ocieplen, połączonych z zanikaniem zmarzliny w okresie interpleniglacjalnym 50-30 ka BP i okresie późnoglacjalnym 15-11 ka BP (Korup i in. 2010; Gębica i in. 2015). Wtedy wiele stoków uległo przeobrażeniom, niekiedy czytelnym do dziś. Następowała wówczas przebudowa obiegu wody na stokach związana z zanikiem zmarzliny. Większość stoków dzisiejszego piętra leśnego zachowało nadal cechy rzeźby tego ostatniego okresu peryglacjalnego. Jedynie w korzystnych warunkach geologicznych doszło do przekraczania na stokach wartości progowych przez holoceńskie procesy erozyjne, sufozyjne a zwłaszcza przez ruchy osuwiskowe (Margielewski 2006; Starkel $i$ in. 2013).

Niestety w minimalnym stopniu zwraca się uwagę na przyczyny braku czwartorzędowych pokryw zwietrzelinowych i koluwialnych z okresów starszych od ostatniego glacjału i holocenu. Tymczasem te wielokrotne okresy ociepleń i ochłodzeń czwartorzędowych musiały znaleźć odbicie w glebach interglacjalnych czy w koluwiach okresów chłodnych. Wysoko wyniesione grzbiety były zlodowacone, rozległe było natomiast piętro krioniwalne w okresach ochłodzeń.

Rzeźba wyniesionych masywów musiała być zatem przekształcana i obniżana wielokrotnie. Denudacji sprzyjało pogłębianie dolin w wyniku ruchów podnoszących, które w Karpatach sięgały rzędu $100 \mathrm{~m} \mathrm{w}$ skali czwartorzędu (Starkel 1965; Zuchiewicz 2010).

Poligeniczny i polichroniczny charakter mają też stopnie erozyjno-akumulacyjnych teras w dolinach górskich, które zostały przekształcone przez denudację krawędzi i akumulację pokryw stokowych w wypukło-wklęsłe stoki (Starkel 2014). Pogłębianiu dużych dolin towarzyszyło rozcinanie lejów źródłowych i ożywienie procesów osuwiskowych.

Niemal zupełny brak śladów starszych od ostatniego glacjału pokryw glebowych i stokowych, poza formami glacjalnymi w wyższych górach i aluwiami na przedpolu, świadczy o efektywności procesów ostatniego cyklu, który 
zatarł $\mathrm{w}$ górach średnich ślady starszych faz peryglacjalnych. Jest to równocześnie dowodem plejstoceńskiej poligeniczności i polichroniczności rzeźby stoków i dolin, szczególnie na mniej odpornych ogniwach karpackiego fliszu (Starkel 2014). Pośrednim przykładem zależności stopnia przekształceń od odporności podłoża może być zachowanie fragmentu staroplejstoceńskiej terasy, o wysokości do $100 \mathrm{~m}$ ze żwirami, położonej na odpornej ławicy piaskowcowej a w sąsiedztwie wykształcenie się na małoodpornych łupkach pagórkowatej rzeźby denudacyjnej, wznoszącej się jedynie do $50 \mathrm{~m}$ nad poziom współczesnych koryt rzek (Starkel 1965).

\section{Poligeneza i polichroniczność istniejącej rzeźby gór}

Rzeźba gór i wyżyn południowej Polski ma stare założenia, jest zarówno poligeniczna jak i polichroniczna. Piętrowość wysokościowa karpackich grzbietów skorelowana $\mathrm{z}$ ewolucją sterasowanych zboczy dolin i osadami korelatnymi na przedpolu gór wskazuje na wiek założeń, obecność ruchów podnoszących i zmian klimatu (Klimaszewski 1965; Starkel 1969; Minar i in. 2005; Zuchiewicz 2011). Badania Jankowskiego i Margielewskiego (2014) wykazały związek kilku wyższych poziomów ze strukturą podłoża a zwłaszcza odpornością (a nie fazami młodszych ruchów podnoszących), która odzwierciedla zróżnicowany przestrzennie etap regresji nasuwczej związanej z kolapsem grawitacyjnym.

Denudacja realizowana w czwartorzędowych rytmach zmian klimatu $\mathrm{z}$ udziałem wielokrotnych ekspansji i recesji zmarzliny zadecydowała o współczesnym wyglądzie poligenicznej i polichronicznej rzeźby gór i wyżyn.

Określenie wieku korzeni istniejącej rzeźby jest trudne, gdyż odziedziczona rzeźba ulegała ciągłej adaptacji. O ile pogłębianie czwartorzędowe dolin zapisane jest $\mathrm{w}$ piętrowości teras erozyjno-akumulacyjnych, to w rzeźbie denudacyjnej form międzydolinnych najwyraźniej zapisany jest ostatni cykl glacjalno-interglacjalny. Obserwacje procesów współczesnych pokazują, że większość form stanowi efekt współdziałania różnych procesów, a pośród nich motorem w okresach zimnych były sekularne procesy związane ze zmarzliną a $\mathrm{w}$ okresach ociepleń są zdarzenia ekstremalne o dużym natężeniu. W zdarzenia te obfitują na ogół epizody szyb- kich zmian klimatycznych (por. Starkel $\mathrm{i}$ in. 2013, 2017).

Z kolei duża odporność podłoża może decydować o tym, że obok form poligenicznych adaptowanych do późniejszych zmian mogły zachować się formy stare w niezmienionym kształcie, spotykane najczęściej w starych masywach krystalicznych.

\section{Literatura}

Czudek T. 2011. Two different models of the origin of Pleistocene pediments: an example from the Central Moravian Carpathians, Czech Republic. Geographia Polonica 84, Special Issue, part I: 9-15.

Czudek T., Demek J. 1973. Die Reliefentwicklung während der Dauerfrostbodendegradation. Rozprawy ČSAV 83,2.

Dauksza L., Kotarba A. 1973. An analysis of the influence of fluvial erosion in the development of a landslide slope (using the application of the queing theory). Studia Geomorphologica Carpatho-Balcanica 7: 91-103.

Dziewański J., Starkel L. 1967. Slope covers on the middle terrace at Zabrodzie upon the San. Studia Geomorphologica Carpatho-Balcanica 1: 21-35.

Gębica P., Starkel L., Michczyńska D.J. 2015. Fluvial history of Sub-Carpathian Basins (Poland) during the last cold stage (60-8 cal ka BP). Quaternary International 388: 119-141.

Gil E. 1998. Spływ wody i procesy geomorfologiczne w zlewniach fliszowych podczas gwałtownej ulewy w dniu 7 czerwca 1985. Dokumentacja Geograficzna IGiPZ PAN 11: 85-107.

Gil E., Kotarba A. 1977. Model of slide slope evolution in flysch mountains (an example drawn from the Polish Carpathians). Catena 4: 233248.

Gil E., Starkel L. 1979. Long-term extreme rainfalls and their role in the modelling of flysch slopes. Studia Geomorphologica CarpathoBalcanica 13: 207-220.

Jankowski L., Margielewski W. 2014. Strukturalne uwarunkowania rozwoju rzeźby Karpat zewnętrznych - nowe spojrzenie. Przegląd Geologiczny 62,1: 29-35.

Klimaszewski M. 1965. Views on the geomorphological development of the Polish West Carpathians in tertiary times. Geomorphological Problems of Carpathians, Bratislava: 91-126.

Klimaszewski M. 1971. The effect of solifluction processes on the development of mountain slopes in the Beskidy (Flysch Carpathians). Folia Quaternaria 28: 3-18.

Kłapa M. 1980. Procesy morfogenetyczne i ich związek $\mathrm{z}$ sezonowymi zmianami pogody w oto- 
czeniu Hali Gąsienicowej w Tatrach. Dokumentacja Geograficzna IGiPZ PAN 4: 1-54.

Kotarba A. 1984. Elevational differentiation of slope geomorphic processes in the Polish Tatra Mts. Studia Geomorphologica Carpatho-Balcanica 18: 117-133.

Kotarba A. 1994. Geomorfologiczne skutki katastrofalnych letnich ulew w Tatrach Wysokich. Acta Univ. N. Copernici, Geografia 27: 21-34.

Kotarba A. 1997. Formation of high-mountain talus slopes related to debris-flow activity in the High Tatra Mountains. Permafrost and Periglacial Processes 8,2: 191-204.

Margielewski W. 2006. Records of the LateglacialHolocene palaeoenvironmental changes in landslide forms and deposits of the Beskid Makowski and Beskid Wyspowy Mts. area (Polish Outer Carpathians). Folia Quaternaria 76: 1-149.

Minár J. 2005. Stredohorska roven v Západných Karpátach ako tektoplen: načrt pracovnej hypotézy. Geograficky časopis 55,2: 141-158.

Rączkowska Z. 2007. Współczesna rzeźba peryglacjalna wysokich gór Europy. Prace Geograficzne IGiPZ PAN 212: 1-252.

Starkel L. 1960. Rozwój rzeźby Polskich Karpat fliszowych w holocenie. Prace Geograficzne IG PAN 22: 1-239.

Starkel L. 1965. Rozwój rzeźby polskiej części Karpat Wschodnich. Prace Instytutu Geografii PAN 50: 1-143.

Starkel L. 1969. The age of the stages of development of the relief of the Polish Carpathians in the light of the most recent geological investigations. Studia Geomorphologica CarpathoBalcanica 3: 33-44.

Starkel L. 1976. Zagadnienia młodych ruchów tektonicznych w świetle przeglądowej mapy geomorfologicznej Polski. Sympozjum: Współczesne i neotektoniczne ruchy skorupy ziemskiej w Polsce, vol. II, 1975: 127-133.

Starkel L. 2005. Współczesna rzeźba Polski dziedziczy cechy peryglacjalne. Przegląd Geograficzny 77: 5-13.

Starkel L. 2011. Paradoxies in the development of gullies. Landform Analysis 17: 11-13.

Starkel L. 2014. O niektórych prawidłowościach rozwoju rzeźby gór i ich przedpoli (na przykładzie wybranych gór Eurazji). Wydawnictwo Akademickie SEDNO: 1-386.

Starkel L., Gębica P., Superson J. 2007. Last GlacialInterglacial cycle in the evolution of river valleys in southern and central Poland. Quaternary Science Reviews 26: 2924-1936.
Starkel L., Michczyńska D., Gębica P. 2017. Reflection of climatic changes during Interpleniglacial in geoecosystems of South-Eastern Poland. Geochronometria 44: 202-215.

Starkel L., Michczyńska D., J., Krąpiec M., Margielewski W., Nalepka D., Pazdur A. 2013. Progress in the Holocene chronoclimatostratigraphy of Polish territory. Geochronometria 40,1: 1-21.

Wrońska-Wałach D. 2009. Dendrogeomorphological analysis of a headwater area in the Gorce Mounatins. Studia Geomorphologica Carpatho-Balcanica 43: 97-114.

Ziętara T. 1968. Rola gwałtownych ulew i powodzi w modelowaniu rzeźby Beskidów. Prace Geograficzne IG PAN 60: 1-116.

Zuchiewicz W. 2010. Neotektonika Karpat Polskich i zapadliska przedkarpackiego. Wyd. AGH, Kraków: 1-234.

Zuchiewicz W. 2011. Planation surfaces in the Polish Carpathians: myth or reality. Geographia Polonica 84, Special Issue, part 2: 155-178.

\section{Summary}

Mountain landscapes are the outcome of combined actions of various powers and processes which change their leading role during various stages of evolution. The relief of the Carpathians has features of a polygenic as well as polychronic landscape. On polygenesis we may talk in a double context. We observe, that young forms like gullies or big landslides are developing and expanding by cooperation of various processes (among them flowing water, piping and several types of gravitational movements). Their role may change with the maturation of forms (Fig.1).

The fundamental forms of the existing mountain relief (ridges, valleys etc.) were created mainly in the distant past under varying tectonic as well climatic conditions. Therefore, the mountain relief has not only a polygenic but also polychronic character. The relief created during older epochs has been preserved depending on the resistance of bedrock, which also determines the adaptation to the permanently changing climatic conditions. The most expressive markers of that adaptation in the flysch Carpathians were left by the last glacial-interglacial climatic cycle, during which the markers of the older phases have been effaced. 